\title{
Utilization of Colorectal Cancer Screening among Saudi Elderly Population: A Study from the Saudi National Survey for Elderly Health
}

\author{
Abdullah Khoja ${ }^{1}$, Mohammad Aljawadi ${ }^{2 *}$, Sulaiman A Al-Shammari ${ }^{3}$, Nader \\ N Bokhari ${ }^{4}$, Abdulrahman A Aldarwish ${ }^{5}$, Waleed K Mardini ${ }^{5}$, Tawfik A Khoja ${ }^{6}$
}

\begin{abstract}
Objective: The goal of this study was to measure colorectal cancer screening (CRCS) utilization in Saudi Arabia 's elderly population and to assess the factors associated with CRCS. Methods: The Saudi National Survey for Elderly Health was used to examine CRCS utilization. It is a nationally representative population-based cross-sectional survey that was conducted between 2006-2007. Utilization of CRCS was defined as any colonoscopy during the last five years or fecal occult blood test (FOBT) during the twelve months before the interview. Multivariable logistic regression was used to assess patients' demographics, co-morbidities, number of visits to primary health clinics, and hospital availability and accessibility impact on CRCS. Results: The prevalence of CRCS utilization among Saudi elderly population was $5.64 \%$. The fecal occult blood test was done in $4.4 \%$ of subjects while scope use was performed in $0.55 \%$. In addition, $0.69 \%$ of patients have gone through both FOBT and scope use. Having blood in stools (OR=2.80; 95\% CI: 1.3-6.00), Self-drivers $(\mathrm{OR}=2.52)$ private driver $(\mathrm{OR}=2.1 ; 95 \% \mathrm{CI}: 1.15-3.7)$ having 4 or more visits to primary care centers 1.81 (95\%CI: 1.14-2.86) were positively associated with CRCS utilization. On the other hand, being single was negatively associated with CRCS utilization. Conclusion: In this nationally representative sample CRCS prevalence was very low. According to our findings and in the context of the burden of colorectal cancer on the population, we recommend developing national evidence-based policies and programs that take in consideration easiness of transportation and the availability of primary care centers near to Saudi elderly population.
\end{abstract}

Keywords: Colon cancer- elderly population- Saudi Arabia

Asian Pac J Cancer Prev, 19 (12), 3401-3407

\section{Introduction}

Colorectal cancer (CRC) is considered one of the most common tumors worldwide (Ferlay et al., 2010). At a global level, CRC is regarded as the third most common cancer in males representing $10 \%$ of all cancers and second in females (9.2\%) (Ferlay et al., 2010). In Saudi Arabia, overall, CRC is the second most common reported malignancy. (Mosli and Al-Ahwal, 2012; Zubaidi et al., 2015) It comes first in rank in males and second in females after breast cancer (Saudi Cancer Registry, 2016). The estimated incidence of CRC cases in the East Mediterranean region (EMRO) is 246,000 with estimated 112,000 deaths per year. (World health orgnisation, 2012) Furthermore, the 5-year prevalence during 2012 was 705,000. (World health orgnisation, 2012) Regarding the Age-standardized death rates in the EMRO region,
Saudi Arabia fell in second place and ranked as the 69th worldwide with 8.3 per 100,000 inhabitants in CRC. Around $12.5 \%$ of all males' death and $11.1 \%$ of all females' deaths were attributed to CRC (Ferlay et al., 2010).

Over the years, colorectal cancer screening (CRCS) has been shown to reduce the mortality and morbidity of colon cancer among the general population. (Force, 2008; Richardson et al., 2010; "Screening for colorectal cancer: recommendation and rationale," 2002) Despite the existence of various evidence regarding the clinical impact and cost-effectiveness of CRCS screening, (Frazier et al., 2000; Pignone et al., 2002) this protective measure has been underused amid the gulf cooperation countries (GCC) and high income developing countries (Shareef et al., 2015; Almadi, et al., 2015; Bazarbashi et al., 2014; Bener, 2012; Zubaidi et al., 2015). In the US, CRCS

${ }^{1}$ Department of Public Health and Family Medicine, ${ }^{5}$ College of Medicine, Al Imam Mohammad ibn Saud Islamic University (IMSIU), ' Department of Clinical Pharmacy, College of Pharmacy, ${ }^{3}$ Department of Family and Community Medicine, College of Medicine, King Saud University, ${ }^{4}$ Emergency Medicine, Security Forces Hospital, ${ }^{6}$ Former Director General, Executive Board, Health Ministers' Council for the Gulf Cooperation Council States, Riyadh, Saudi Arabia. *For Correspondence: maljawadi@ksu.edu.sa. Mohammad Aljawadi and Abdullah Khoja have equal contribution in this study 
utilization was estimated to be $53.8 \%$ in 2002 . (Rim et al., 2011) This percentage has been rising over the years from 2004 and 2008 to be $(56.7 \%)$ and $(64.2 \%)$, respectively. Rim et al., (2011) The US Preventive Services Taskforce (USPTF) recommends CRCS using fecal occult blood testing every year, sigmoidoscopy every five years, or colonoscopy every ten years(Almadi et al., 2015). The new recommendations from USPTF included further modalities of CRCS such as fecal immunochemical test, multi-targeted stool DNA test, colonography, flexible sigmoidoscopy combined with the fecal immunochemical test (Bibbins-Domingo et al., 2016). The goal of this study was to measure the utilization of CRCS in Saudi Arabia elderly population and to assess the determinants of utilization based on a nationally representative survey.

\section{Materials and Methods}

The Saudi National Survey for Elderly Health (SNSEH) was used to examine the utilization of CRCS (Khoja et al., 2017). In brief, it is a nationally representative population-based cross-sectional survey that was conducted between 2006-2007. The cohort was followed to assert the survival until June 2015. The inclusion criteria included any Saudi aged 60 years old or over. The selected subjects were contacted for two household visits to conduct personal interviews and perform physical examination and investigation. Data were collected using a structured interview technique and validated questionnaires. Also, structured data forms were also used for obtaining a clinical history, physical examination, and clinical investigation information.

During the interview, subjects were asked about the receipt of FOBT during the prior twelve months or the receipt of any scope to the colon during the last five years prior the interview. The two aforementioned procedures were used to define the utilization of CRCS. The independent variables, determinants of utilization that considered to be included in our analysis were based on Andersen's theoretical framework, data availability and clinical relevance (Andersen and Newman, 1973; Andersen and Newman, 2005). These include patients' factors, comorbidity, the social determinants of health, risk behaviors, the number of visits to Primary health clinics, number of admissions, hospital availability and accessibility.

In analyzing the data, STATA 14 survey command was used. The sampling design and standardized survey weight were considered in calculating the point estimates. Descriptive statistics were reported as mean, standard deviation (SD), frequencies and percentages for the socio-demographic and clinical characteristics.

In exploring factors associated with CRCS utilization, the odds ratios were reported about intervening factors using the bi-variable logistic regression. In addition, a multivariable logistic model fitting with forward, backward and stepwise approaches was used. Finally, AIC, BIC, Hosmer-Lemeshow goodness of fit tests were used to select the best model fitting which was reported in the paper.

Multiple imputation was used to impute the missing data if there was no more than $10 \%$ missingness in an observation. This method provides an advantage over substituting missing values with only a single value such as means or medians. Instead, multiple imputation uses other variables in the dataset to predict the missing value using multivariable regression with missing at random assumption. Then the completed dataset is analyzed. The process is repeated multiple times, 50 times in this study, and the estimates are then pooled together to present the final estimate (Rubin, 1987). Sensitivity assessment of the model was employed to assess the impact of Multiple imputation on the estimates. All statistical analyses were done using STATA 14 ("StataCorp. 2015. Stata Statistical Software: Release 14. College Station, TX: StataCorp LP.,"). The IRB committee in Imam Muhammad Bin Saud Islamic University exempted the study from IRB review (IRB number: HAPO-01-R-011).

\section{Results}

Total of 2,946 participants who represented the thirteen administrative regions of Saudi Arabia were included in the analysis. The mean age was $(70.3 \pm \mathrm{SD}=8.3)$ years, with approximately $60 \%$ of subjects below 70 years. Males constituted $50.4 \%$ of the participants. The Majority were living in urban areas (80\%).

The prevalence of CRCS Utilization among Saudi elderly population was $5.64 \%$. The fecal occult blood test was done in $4.4 \%$ of subjects while scope to the colon was performed in $0.55 \%$. In addition, $0.69 \%$ of patients have gone through both FOBT and colonoscopy. Among subjects who went through CRCS, 16.8\% have reported having blood in stools during the interview. The prevalence of CRCS was 5.9\% among 60-65 years old patients, $6 \%$ among $66-70$ years old and $6.6 \%$ among 71-75 years old $(\mathrm{P}=0.54)$.

In the bi-variable analysis, compared to subjects who were living alone, subjects who lived with the first-degree relative were less likely to go through screening $(4.1 \%$ vs. $8.9 \% ; \mathrm{P}=0.024)$. In addition, there is a proportional relationship between education level and CRCS. For instance, CRCS utilization among illiterate subject was $4.7 \%$ compared to $10 \%$ among intermediate to high school graduate. However, the CRCS prevalence drops to $4.1 \%$ among university degree holders $(\mathrm{P}=0.002)$.

Colorectal cancer screening prevalence was the highest among subjects who had a private driver $(10.7 \%)$ or subjects who drive $(8.0 \%)$ compared to those depending on relatives $(4.0 \%)$ or public transportation $(4.2 \% ; \mathrm{P}=0.025)$. Colorectal cancer screening was $8.5 \%$ among patients who perceived the occurrence of weight loss during the last six months compared to $4.9 \%$ among patients who did not or those who did not know (4.4\%; $\mathrm{P}=0.039)$.

There was a proportional relationship between income and CRCS utilization. For instance, $4.2 \%$ of subjects with an income of $<$ SR2500 undergoes CRCS where it increased to $4.6 \%$ among subjects with income range 2,500-4,999. A similar trend was seen among all higher income groups. The highest utilization (13.7\%) was among subjects with monthly income more than 10,000.

In the multivariable logistic regression, neither age 
DOI:10.31557/APJCP.2018.19.12.3401

Colorectal Cancer Screening in Saudi Older Adults

Table 1. Characteristics of Saudi Elderly Population by Colorectal Cancer Screening Status in 2006-2007 $(\mathrm{n}=2,946)$

\begin{tabular}{|c|c|c|c|c|}
\hline \multirow[t]{2}{*}{ Characteristics } & \multicolumn{2}{|c|}{$\begin{array}{l}\text { Colorectal cancer } \\
\text { screening }\end{array}$} & \multirow{2}{*}{$\begin{array}{c}\mathrm{N}=2,946 \\
\text { Total } \\
\mathrm{n}(\operatorname{col} . \%)\end{array}$} & \multirow[t]{2}{*}{ P-value } \\
\hline & $\begin{array}{c}\text { No } \\
\mathrm{n}(\text { Row \%) }\end{array}$ & $\begin{array}{c}\text { Yes } \\
\mathrm{n}(\text { Row \%) }\end{array}$ & & \\
\hline Total frequencies & $2780(94.4)$ & $166(5.6)$ & $2946(100.0)$ & \\
\hline Age (Years) & & & & 0.417 \\
\hline $60-65$ & $1043(94.1)$ & $65(5.9)$ & 1109 (37.6) & \\
\hline $66-70$ & $635(94.0)$ & $40(6.0)$ & 675 (22.9) & \\
\hline $71-75$ & 455 (93.4) & $32(6.6)$ & $487(16.5)$ & \\
\hline $76-80$ & $318(96.7)$ & $11(3.3)$ & $329(11.2)$ & \\
\hline $81-85$ & $167(93.8)$ & $11(6.2)$ & $178(6.0)$ & \\
\hline $86-90$ & 97 (97.4) & $3(2.6)$ & $99(3.4)$ & \\
\hline$>90$ & $65(94.2)$ & $4(5.8)$ & $69(2.3)$ & \\
\hline Gender & & & & 0.704 \\
\hline Female & $1382(94.6)$ & $78(5.4)$ & $1461(49.6)$ & \\
\hline Male & $1398(94.1)$ & $88(5.9)$ & $1485(50.4)$ & \\
\hline Urban vs. Rural & & & & 0.807 \\
\hline Urban & $2221(94.2)$ & $136(5.8)$ & $2357(80.0)$ & \\
\hline Rural & 559 (94.9) & $30(5.1)$ & $589(20.0)$ & \\
\hline \multicolumn{3}{|c|}{ Number of persons live with the subject? } & & 0.024 \\
\hline None & $1372(95.9)$ & $59(4.1)$ & $1431(48.6)$ & \\
\hline Yes, First degree & $592(91.1)$ & $58(8.9)$ & $650(22.1)$ & \\
\hline Yes, Other relative & $815(94.3)$ & $50(5.7)$ & $865(29.4)$ & \\
\hline \multicolumn{3}{|c|}{ Monthly income (Saudi Riyal, 2007) } & & $<0.001$ \\
\hline$>10,000$ & $144(86.3)$ & $23(13.7)$ & $166(5.6)$ & \\
\hline $9,999-7,500$ & $109(88.6)$ & $14(11.4)$ & $122(4.2)$ & \\
\hline $7,499-5,000$ & $253(90.3)$ & $27(9.7)$ & $280(9.5)$ & \\
\hline $4,999-2,500$ & $659(95.4)$ & $32(4.6)$ & $691(23.5)$ & \\
\hline$<2,500$ & $1616(95.8)$ & $71(4.2)$ & $1686(57.2)$ & \\
\hline Level of education & & & & 0.002 \\
\hline Illiterate & $1955(95.3)$ & $95(4.7)$ & $2050(69.6)$ & \\
\hline $\begin{array}{l}\text { Less than } 6 \text { years } \\
\text { of education }\end{array}$ & $593(92.4)$ & $49(7.6)$ & $642(21.8)$ & \\
\hline $\begin{array}{l}\text { Intermediate to } \\
\text { High school }\end{array}$ & $172(90.0)$ & $19(10.0)$ & $191(6.5)$ & \\
\hline $\begin{array}{l}\text { University or } \\
\text { higher }\end{array}$ & $60(95.9)$ & $3(4.1)$ & $63(2.1)$ & \\
\hline \multicolumn{3}{|c|}{ Who provides your transportation? } & & 0.025 \\
\hline Myself & $774(92.0)$ & $67(8.0)$ & $840(28.5)$ & \\
\hline Private Driver & 209 (89.3) & $25(10.7)$ & $234(7.9)$ & \\
\hline Family or Friends & $1318(96.0)$ & $55(4.0)$ & $1373(46.6)$ & \\
\hline $\begin{array}{l}\text { Public } \\
\text { Transportation }\end{array}$ & $322(95.8)$ & $14(4.2)$ & $336(11.4)$ & \\
\hline Others & $158(96.9)$ & $5(3.1)$ & $163(5.5)$ & \\
\hline Currently Smoking & & & & 0.713 \\
\hline No & $2616(94.4)$ & $155(5.6)$ & $2771(94.0)$ & \\
\hline Yes & $164(93.7)$ & $11(6.3)$ & $175(6.0)$ & \\
\hline BMI WHO categories & & & & 0.038 \\
\hline Less than 18.5 & $50(93.6)$ & $3(6.4)$ & $54(1.8)$ & \\
\hline From 18.5 to 25 & $818(96.5)$ & $29(3.5)$ & $848(28.8)$ & \\
\hline From 25 to 30 & $1043(94.8)$ & $57(5.2)$ & $1100(37.3)$ & \\
\hline More than 30 & 868 (91.9) & $77(8.1)$ & $945(32.1)$ & \\
\hline Diabetes mellitusË & & & & $<0.001$ \\
\hline NO & $1400(95.8)$ & $61(4.2)$ & $1461(49.6)$ & \\
\hline Yes & $1380(92.9)$ & $105(7.1)$ & $1485(50.4)$ & \\
\hline
\end{tabular}

Table 1. Continued

\begin{tabular}{|c|c|c|c|c|}
\hline \multirow[t]{2}{*}{ Characteristics } & \multicolumn{2}{|c|}{$\begin{array}{l}\text { Colorectal cancer } \\
\text { screening }\end{array}$} & \multirow{2}{*}{$\begin{array}{c}\mathrm{N}=2,946 \\
\text { Total } \\
\mathrm{n}(\mathrm{col} . \%)\end{array}$} & \multirow[t]{2}{*}{ P-value } \\
\hline & $\begin{array}{c}\text { No } \\
\text { n (Row \%) }\end{array}$ & $\begin{array}{c}\text { Yes } \\
\text { n (Row \%) }\end{array}$ & & \\
\hline \multicolumn{4}{|l|}{ CognitionÀ } & $<0.001$ \\
\hline Normal & $2278(94.4)$ & $135(5.6)$ & $2413(81.9)$ & \\
\hline Mild impairment & $342(97.8)$ & $8(2.2)$ & $350(11.9)$ & \\
\hline $\begin{array}{l}\text { Moderate } \\
\text { impairment }\end{array}$ & $112(93.7)$ & $8(6.3)$ & $119(4.1)$ & \\
\hline Severe impairment & $48(74.5)$ & $16(25.5)$ & $64(2.2)$ & \\
\hline \multicolumn{4}{|c|}{ Perception of weight loss in last 6 months } & 0.039 \\
\hline No & $1917(95.1)$ & $100(4.9)$ & $2017(68.5)$ & \\
\hline Yes & $566(91.5)$ & $53(8.5)$ & $618(21.0)$ & \\
\hline I do not know & $297(95.6)$ & $14(4.4)$ & $311(10.6)$ & \\
\hline \multicolumn{4}{|l|}{ Bloody stool } & $<0.001$ \\
\hline No & $2728(94.6)$ & $156(5.4)$ & $2884(97.9)$ & \\
\hline Yes & $52(83.2)$ & $10(16.8)$ & $62(2.1)$ & \\
\hline \multicolumn{4}{|c|}{ Visiting primary health care in the last 12 months } & 0.419 \\
\hline No visits & $857(96.2)$ & $34(3.8)$ & $890(30.2)$ & \\
\hline $1-3$ visit & $424(92.6)$ & $34(7.4)$ & $458(15.5)$ & \\
\hline 4 or more visits & $1500(93.8)$ & $98(6.2)$ & $1598(54.2)$ & \\
\hline
\end{tabular}

^ BMI, Body mass index; WHO: World Health Organization; $\sigma$, Based on joint national commission VII; $\not \subset$ based on History of DM, history of DM Drugs or DM from fasting plasma glucose, $\mathbf{\aleph}$ based on Short Portable Mental Status Questionnaire (SPMSQ)

nor gender has any significant effect on the odds of utilization after controlling for other factors. On the other hand, being single was negatively associated with CRCS utilization compared to patients who were married to a single wife (Odds Ratio (OR) $=0.11 ; 95 \%$ confidence interval (95\% CI): 0.01-0.84) (Table 2).

Considering the relationship between comorbidities and CRCS, having diabetes mellitus did not have a significant effect on the odds of CRCS (OR=1.37; 95CI\%: 0.97-1.94). However, having blood in stools was positively associated with performing $\mathrm{CRCS}(\mathrm{OR}=2.80$; 95\% CI: 1.3-6.00).

With regards to monthly income, there was no difference between subjects whose income was 2,500-4,999 and subjects with an income $<2,500$ $(\mathrm{OR}=0.94 ; 95 \% \mathrm{CI}: 0.60-1.51)$. However, all higher income categories were associated with increased odds of CRCS.

Compared to subjects who were given a ride by a relative, subjects who drive by themselves were 2.52 times more likely to perform CRCS after controlling for other factors. A similar trend was seen among subjects who have a private driver $(\mathrm{OR}=2.1 ; 95 \% \mathrm{CI}: 1.15-3.7)$ compared to subjects who were given a ride by a relative. In contrast, there was no difference between taking public transportation and subjects who were given a ride by a relative $(\mathrm{OR}=0.99 ; 95 \%$ CI: $0.47-2.1)$.

Concerning the relationship between the number of visits to a primary health care center or a private clinic and the odds of performing CRCS, subjects who had 1 to 3 visits to these sites during the last 12 months did not differ significantly from subjects who did not go to these centers $(\mathrm{OR}=1.6,95 \%$ CI: 0.91-2.83). However, subjects who had 4 or more visits were 1.81 (95\% CI:1.14-2.86) 
Table 2. Multivariate Logistic Regression of Factors Associated with Colorectal Cancer Screening among Saudi Older Adult in $2007(\mathrm{~N}=2,946)$

\begin{tabular}{|c|c|c|}
\hline Characteristics & OR & $95 \% \mathrm{CI}$ \\
\hline \multicolumn{3}{|l|}{ Age } \\
\hline $66-70$ & 0.96 & $(0.62-1.49)$ \\
\hline $71-75$ & 1.32 & $(0.83-2.12)$ \\
\hline $76-80$ & 0.83 & $(0.43-1.59)$ \\
\hline $81-85$ & 1.58 & $(0.78-3.21)$ \\
\hline $86-90$ & 0.70 & $(0.21-2.42)$ \\
\hline$>90$ & 1.63 & $(0.45-5.93)$ \\
\hline \multicolumn{3}{|l|}{ Sex (Ref: Male) } \\
\hline Female & 0.95 & $(0.55-1.65)$ \\
\hline \multicolumn{3}{|l|}{ Marital Status (Ref: Married to single wife) } \\
\hline Polygamy & 1.00 & $(0.64-1.57)$ \\
\hline Widow & 1.31 & $(0.76-2.24)$ \\
\hline Single & 0.11 & $(0.01-5.84)$ \\
\hline Separated & 0.63 & $(0.14-2.76)$ \\
\hline \multicolumn{3}{|l|}{ Number of persons live with the subject (Ref: No) } \\
\hline Yes, 1st degree & 2.14 & $(1.43-3.28)^{* * *}$ \\
\hline Yes, other & 1.40 & $(0.93-2.12)$ \\
\hline \multicolumn{3}{|l|}{ Monthly income (Saudi Riyal, 2007; Ref: $<2,500$ ) } \\
\hline$>10,000 \mathrm{SR}$ & 4.42 & $(2.32-8.41)^{* * *}$ \\
\hline $9,999-7,500 \mathrm{SR}$ & 2.62 & $(1.33-5.15)^{* * *}$ \\
\hline $7,499-5,000 \mathrm{SR}$ & 2.13 & $(1.26-3.58)^{* * *}$ \\
\hline $4,999-2,500 \mathrm{SR}$ & 0.95 & $(0.60-1.51)$ \\
\hline \multicolumn{3}{|l|}{ Level of education (Ref: Illiterate) } \\
\hline Less than 8years & 1.04 & $(0.68-1.62)$ \\
\hline Intermediate to High school & 0.95 & $(0.51-1.78)$ \\
\hline University or higher & 0.25 & $(0.06-9.94)$ \\
\hline \multicolumn{3}{|c|}{ Who provides your transportation? (Ref: by Relative) } \\
\hline Myself & 2.52 & $(1.48-4.28)^{* * *}$ \\
\hline Private Driver & 2.09 & $(1.15-3.78)^{*}$ \\
\hline Public Transportation & 0.99 & $(0.47-2.57)$ \\
\hline Others & 0.58 & $(0.20-1.68)$ \\
\hline \multicolumn{3}{|l|}{ Smoking (Ref: None-smoker) } \\
\hline Ever Smoked & 1.14 & $(0.58-2.23)$ \\
\hline \multicolumn{3}{|l|}{ Body mass index $(\mathrm{BMI}) \diamond$} \\
\hline Less than 18.5 & 2.51 & $(0.71-8.89)$ \\
\hline From 18.5 to 25 & 1.27 & $(0.79-2.82)$ \\
\hline From 25 to 30 & 2.34 & $(1.47-3.75)^{* * *}$ \\
\hline \multicolumn{3}{|l|}{ More than 30} \\
\hline Diabetes Mellitus (DM) $\not \subset$ & 1.37 & $(0.97-1.94)$ \\
\hline $\begin{array}{l}\text { Perception of weight loss in last } 6 \text { months (ref: } \\
\text { No) }\end{array}$ & 1.98 & $(1.34-2.93)^{* * *}$ \\
\hline Blood in stool & 2.80 & $(1.30-6.41)^{* *}$ \\
\hline \multicolumn{3}{|l|}{ Primary health care visits (ref: none) } \\
\hline 1 to 3 & 1.61 & $(0.91-2.84)$ \\
\hline 4 or more & 1.81 & $(1.14-2.86)^{*}$ \\
\hline \multicolumn{3}{|l|}{ Depression $\nabla$} \\
\hline Score more than 5 (suggestive of depression) & 1.64 & $(1.10-2.45)^{* * *}$ \\
\hline Score more than 10 (almost always depression) & 1.61 & $(0.70-3.68)$ \\
\hline Observations: & 2,946 & \\
\hline
\end{tabular}

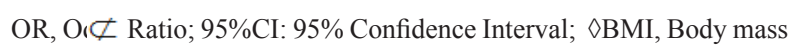
index; , Based on Histdry of DM, history of DM Drugs or DM from fasting plasma glucose; , Based on geriatrics depression scale; *, $\mathrm{p}<0.05 ; * * \mathrm{p}<0.01 ; * * *, \mathrm{p}<0.001$ times more likely to perform CRCS than subjects who did not have any visits when we controlled for comorbidities and other variables. Finally, both numbers of healthcare service centers and the availability and accessibility to a hospital did not have any effect on the odds of performing CRCS.

\section{Discussion}

In this nationally representative sample of Saudi elderly population that included 2,946 subjects, the adoption of CRCS was very low (5.6\%). In comparison to the US adult population, around the same period, CRCS was performed in $64 \%$ of patients between the age of 50 and 75 in a national survey that included all the 50 states and DC area (Josephet al., 2012). Furthermore, among the Saudi elderly population, the percentage of subjects who had FOBT was $5.0 \%$ compared to $11.7 \%$ among the subjects in the US national survey (Joseph et al., 2012). The very low CRCS prevalence suggests the need for national evidence-based screening policy and program with all its related public awareness, promotion, and clinical intervention and management activities. Such a program is crucial since colorectal cancer is one of the most reported cancers in both gender and the fact the benefit of screening has been established in reducing both incidence and mortality. (Alsaneaet al., 2015; Whitlocket al., 2008)

To date, in Saudi Arabia, no national data has documented the adoption of CRCS among Saudi elderly population. Although the recommended screening age starts from 50 with a suggestion from local studies that in Saudi Arabia the age cutoff should be around 45 years, no national data has looked at the adoption of screening among other eligible age groups. (Alsanea, 2014; Alsaneaet al., 2015)

From a public health prespective, as the primary governing body for healthcare in Saudi Arabia, the ministry of health is in an excellent position to take the lead in developing evidence-based programs, population-oriented interventions and reviewing the recently developed national guidelines regrading CRC prevention (Bazarbashi et al., 2014). However, the perception of Saudi citizens toward CRC screening is also important. A recent survey of 500 Saudi citizens demonstrated that around $70 \%$ of them were "willing to undergo CRC screening" and almost $57 \%$ believed that CRCS is not embarrassing. These results indicate that social acceptance to CRCS does exist among Saudi citizens (Almadi et al., 2015; Alsanea, 2015) which should have a positive impact on the success of any related intervention. Further studies regarding Saudi citizens' perception toward CRC screening should be conducted to understand the eligible population better.

In the multivariable logistic regression, neither age nor gender has any significant effect on the odds of CRCS. This finding is most likely due to the low adoption rate of CRCs in general which is translated to a lower sample size needed to determine the effect of age and gender on CRCS adoption. Nevertheless, in a US study that included 27,068 patients $>70$ years, there was an inverse relationship 
between age and CRCS 2-year cumulative incidence. Age itself is an indicator of the health status of individuals since older age is usually associated with more comorbidities. More importantly, in the study above, the investigators found that the number of outpatients visits predicted CRCS better than health status measured by Charlson comorbidity score (CCS). For instance, the authors stated that "patients with severe comorbidity and $>4$ visits had similar or higher screening rates than healthier patients with fewer visits" (Walter et al., 2009). In this study, the same trend was seen in that subjects who had 1 to 3 visits to these sites during the last 12 months are most likely to undergoes CRCS compared individuals who did not go to these centers $(\mathrm{OR}=1.6,95 \% \mathrm{CI}$ : 0.91-2.83). Moreover, the result showed a statistically significant difference between subjects who had 4 or more visits as they were 1.81 times more likely to perform CRCS than subjects who did not have any visits. The effect of the number of visits was independent of the effect of the number of health care service centers, the availability and accessibility to a hospital, comorbidities and other determinants.

Being accessible and near patients, primary care centers (PPCs) across KSA with innovative and cost-effective screening modalities can play a vital role to serve as the center of screening programs. This systematic screening supported by a created office policy that includes patients risk stratification, availability of medical resources and patients' preference screening method has been proposed in a joint report from the American cancer society and the national colorectal cancer roundtable to increase CRCS (Sarfaty and Wender, 2007). In addition, such an approach maximizes the rate of CRCS while reducing the number of unnecessary screenings. (Levin et al., 2011) Moreover, in a study that looked at factors associated with CRCS, the odds of screening was $31 \%$ higher among patients who have a primary care generalist compared to other specialists (OR: 1.31; 95\% confidence interval, 1.12-1.53) (O’Malley et al., 2005) emphasizing the potential that PCCs have as providers for CRCS.

Being single was negatively associated with being screened compared to patients who were married to a single wife (Odds Ratio $(\mathrm{OR})=0.11 ; 95 \%$ confidence interval (95\%CI): (0.01-0.84)). Social support is essential to individuals; especially older adults who may suffer from multiple comorbidities and require frequent reminders. However, a study that included 500 Saudi citizens (mean age $=41 ; \mathrm{SD}=10.7$ ), Almadi et al., (2015) did not find any association between marital status and the willingness to undergo CRCS. The difference between the two studies is most likely due to the small sample size and younger age of Almadi's study. Like the presented results, in the behavioral risk factor surveillance system 2010 survey that included 230,300 participants between 50 and 75 years old, the investigators found that subjects who were never married were 0.87 times (95\% CI: 0.81-0.93) less likely to be screened compared to individuals who were married (El-Haddadet al., 2015). Marriage creates a sense of responsibility from the individual toward the other partner. Such responsibly has been seen in the form of spouses encouraging frequent monitoring of health status, promoting health-related decisions and providing emotional support. (Blom et al., 2008; Kuan-Chi, 2010; van Jaarsveld et al., 2006)

Several studies reported that DM might increase the risk of colorectal cancer. (Guraya, 2015; Sun and Yu, 2012; Woo et al., 2016; Wu et al., 2013) In this cohort, people with diabetes were $37 \%$ more likely to perform CRCS. Nevertheless, DM did not show a significant effect on the odds of CRCS $(\mathrm{OR}=1.37$; 95CI\%: 0.97-1.94) which could be due to low health literacy among subjects as almost $70 \%$ of subjects were illiterate. On the other hand, having blood in stools was positively associated with performing CRCS (OR=2.80; 95\%CI: 1.3-6.00). Blood in stools is an alarming sign for many diseases from a single fissure to colorectal cancer. Such symptom alert individuals to seek medical care and hence create an opportunity to offer CRCS to subjects.

Income greater than SR4,999 was associated with increased odds of CRCS. As an indicator of socioeconomic status, many studies reported lower adherence to CRCS with low income and areas with high poverty rate. (" $<$ Enhancing Use of Clinical Preventive Services Among Older Adults - Closing the Gap.pdf >,"; Frederiksen et al., 2010; Schootman et al., 2006) In this study, the income of SR5,000 was the cutoff after which the odds of CRCS increased compared to less than SR2,500.

Lack of transportation to a health care facility has been looked at as a barrier of CRCS (Green et al., 2008; Ojinnaka et al., 2015; Patel et al., 2012; Quicket al., 2013) For instance, Quick et al., (2013) reported that transportation was an issue when the subject has to rely on someone else to reach the health care facility or go back home after the appointment. In this study, compared to subjects who were given a ride by a relative, subjects who drive by themselves were 2.52 times more likely to perform CRCS. A similar trend was seen among subjects who have a private driver $(\mathrm{OR}=2.1 ; 95 \% \mathrm{CI}: 1.15-3.7)$ compared to subjects who were given a ride by a relative. In contrast, there was no difference between taking public transportation and subjects who were given a ride by a relative $(\mathrm{OR}=0.99 ; 95 \% \mathrm{CI}: 0.47-2.1)$. The later can be explained by the lag of public transportation development in Saudi Arabia.

Since both public transportation and relying on someone else require prior arrangement which may not be feasible, innovative approaches to transportation should be adopted. Possible approaches are providing transportation by the healthcare facilities, homecare, reimbursement for using new methods of transportation such as transportation network companies (e.g., as "UBER") to facilitate transportation to the healthcare facility. The ministry of health in KSA has used this approach to maximize the rate of influenza and meningitis vaccinations before the Hajj season (Ministry of Health, 2016). Further studies regarding possible approaches to maximize CRCS rate by minimizing the burden of transportation is warranted.

Our study has its limitations; first, the old data may not reflect the current rate of CRCS in Saudi Arabia. However, it is critical to establish a national baseline prevalence of CRCS among Saudi elderly population to determine whether the adoption rate is going up or down in 2017 and later. In addition, setting up the baseline is essential 
to determine the effect of any public interventions, such as CRC national guidelines, on the adoption rate itself. Second, due to the cross-sectional nature of the study, the temporality between CRCS tests and history of blood in the stool cannot be determined. Consequently, for patients who reported blood in stool; there is a possibility that the performed scopes to the colon were diagnostics rather than screening. Nevertheless, the overall very low prevalence of CRCS indicates the importance of creating a national plan to improve CRCS adoption in Saudi Arabia.

Although the recommendations for CRCS mainly limited to 75 years old, we opt to include all the study population to provide a detailed picture and a benchmark to compare with other settings; especially that most of the individuals in the older adult population were less than 75 years old. In addition, the utilization of multivariable logistic regression would control for the effect of other age groups on CRCS utilization.

In conclusion, in this nationally representative sample of Saudi elderly population, the prevalence of CRCS was very low. According to our findings and in the context of the burden of colorectal cancer on the population, we recommend developing national evidence-based policy and program for cancer screening, CRCS that account for the social determinant of health in addition to the health system factors. Further studies and more data related to the prevalence and burden of the condition, the barriers to screening utilization, and condition management at the national level are needed in order to develop and adopt cost-effective and evidence-based interventions for this population. Furthermore, this study supports prior recommendation to use patient, provider and system level intervention to improve the uptake of CRCS utilization (Alqahtani and Khoja, 2015).

\section{References}

Almadi MA, Mosli MH, Bohlega MS, et al (2015). Effect of public knowledge, attitudes, and behavior on willingness to undergo colorectal cancer screening using the health belief model. Saudi J Gastroenterol, 21, 71-7.

Alqahtani S, Khoja A (2015). Colorectal cancer screening program: a needed intervention in Saudi Arabia. Asian Pac $J$ Cancer Prev, 16, 7391.

Alqahtani S, Khoja A (2015). Colorectal cancer screening program: a needed intervention in Saudi Arabia. Asian Pac $J$ Cancer Prev, 16, 7391.

Alsanea N (2014). The dilemma of the threshold age to start screening for colorectal cancer in Saudi Arabia. Saudi $J$ Gastroenterol, 20, 141-2.

Alsanea N, Abduljabbar AS, Alhomoud S, et al (2015). Colorectal cancer in Saudi Arabia: incidence, survival, demographics and implications for national policies. Ann Saudi Med, 35, 196-202.

Alsanea N, Almadi MA, Abduljabbar AS, et al (2015). National guidelines for colorectal cancer screening in Saudi Arabia with strength of recommendations and quality of evidence. Ann Saudi Med, 35, 189-95.

Alsanea NA (2015). The acceptability of screening for colorectal cancer in Saudi Arabia: myths busted. Saudi J Gastroenterol, 21, 59.

Andersen R, Newman JF (1973). Societal and individual determinants of medical care utilization in the United States.
Milbank Mem Fund Q Health Soc, 51, 95-124.

Andersen R, Newman JF (2005). Societal and individual determinants of medical care utilization in the United States. Milbank Q, 83, 10.1111/j.1468-0009.2005.00428.x.

Bazarbashi SN, Alzahrani AM, Rahal MM, et al (2014). Saudi oncology society clinical management guideline series: Colorectal cancer 2014. Saudi Med J, 35, 1538-44.

Bener A (2012). Consanguineous marriages and their effects on common adult diseases: studies from an endogamous population. Cancer, 10, 9.0.

Bibbins-Domingo K, Grossman DC, Curry SJ, et al (2016). Screening for colorectal cancer: US preventive services task force recommendation statement. JAMA, 315, 2564-75.

Blom J, Yin L, Liden A, et al (2008). Toward understanding nonparticipation in sigmoidoscopy screening for colorectal cancer. Int J Cancer, 122, 1618-23.

El-Haddad B, Dong F, Kallail KJ, Hines RB, Ablah E (2015). Association of marital status and colorectal cancer screening participation in the USA. Colorectal Dis, 17, 108-14.

Enhancing Use of Clinical Preventive Services Among Older Adults - Closing the Gap.pdf.

Ferlay J, Shin HR, Bray F, et al (2010). Estimates of worldwide burden of cancer in 2008: GLOBOCAN 2008. Int J Cancer, 127, 2893-2917.

Force USPST (2008). Screening for colorectal cancer: U.s. preventive services task force recommendation statement. Ann Intern Med, 149, 627-37.

Frazier AL, Colditz GA, Fuchs CS, Kuntz KM (2000). Cost-effectiveness of screening for colorectal cancer in the general population. JAMA, 284, 1954-61.

Frederiksen BL, Jorgensen T, Brasso K, Holten I, Osler M (2010). Socioeconomic position and participation in colorectal cancer screening. Br J Cancer, 103, 1496-1501.

Green AR, Peters-Lewis A, Percac-Lima S, et al (2008). Barriers to screening colonoscopy for low-income Latino and white patients in an urban community health center. J Gen Intern Med, 23, 834-40.

Guraya SY (2015). Association of type 2 diabetes mellitus and the risk of colorectal cancer: A meta-analysis and systematic review. World J Gastroenterol, 21, 6026-31.

Joseph DA, King JB, Miller JW, Richardson LC (2012). Prevalence of colorectal cancer screening among adultsbehavioral risk factor surveillance system, United States, 2010. MMWR Suppl, 61, 51-6.

Khoja AT, Aljawadi MH, Al-Shammari SA, et al (2017). The health of Saudi older adults; results from the Saudi National Survey for Elderly Health (SNSEH) 2006-2015. Saudi Pharmaceutical J, doi:https://doi.org/10.1016/j. jsps.2017.11.008

Kuan-Chi Lai BAS (2010). Marital status and colon cancer stage at diagnosis. Clin Colorectal Cancer, 7, 5-11.

Levin TR, Jamieson L, Burley DA, et al (2011). Organized colorectal cancer screening in integrated health care systems. Epidemiol Rev, 33, 101-10.

Ministry of Health K oSA (2016). In collaboration with Uber, $\mathrm{MOH}$ to launch vaccination service at homes. Retrieved from http://www.moh.gov.sa/en/Ministry/MediaCenter/ News/Pages/News-2016-08-18-002.aspx.

Mosli MH, Al-Ahwal MS (2012). Colorectal cancer in the Kingdom of Saudi Arabia: need for screening. Asian Pac J Cancer Prev, 13, 3809-13.

O’Malley AS, Forrest CB, Feng S, Mandelblatt J (2005). Disparities despite coverage: gaps in colorectal cancer screening among Medicare beneficiaries. Arch Intern Med, 165, 2129-35.

Ojinnaka C, Vuong A, Helduser J, et al (2015). Determinants of variations in self-reported barriers to colonoscopy among 
uninsured patients in a primary care setting. J Community Health, 40, 260-70.

Patel K, Hargreaves M, Liu J, et al (2012). Factors influencing colorectal cancer screening in low-income African Americans in Tennessee. J Community Health, 37, 673-9. doi:10.1007/s10900-011-9498-8

Pignone M, Saha S, Hoerger T, Mandelblatt J (2002). Cost-effectiveness analyses of colorectal cancer screening: a systematic review for the US Preventive Services Task Force. Ann Intern Med, 137, 96-104.

Quick BW, Hester CM, Young KL, Greiner KA (2013). Self-reported barriers to colorectal cancer screening in a racially diverse, low-income study population. J Community Health, 38, 285-92.

Richardson L, Rim S, Plescia M (2010). Vital signs: colorectal cancer screening among adults aged 50-75 years-United States, 2008. MMWR Morb Mortal Wkly Rep, 59, 808-12.

Rim SH, Joseph DA, Steele CB, et al (2011). Colorectal cancer screening-United States, 2002, 2004, 2006, and 2008. MMWR Surveill Summ, 60, 42-6.

Rubin DB ( 1987). Multiple imputation for nonresponse in surveys. New York: Wiley, 17-9.

Sarfaty M, Wender R (2007). How to increase colorectal cancer screening rates in practice. CA Cancer J Clin, 57, 354-66.

Schootman M, Jeffe DB, Baker EA, Walker MS (2006). Effect of area poverty rate on cancer screening across US communities. J Epidemiol Community Health, 60, 202-7.

StataCorp (2015). Stata Statistical Software: Release 14. College Station, TX: StataCorp LP. Retrieved from http://www. stata.com/.

Sun L, Yu S (2012). Diabetes mellitus is an independent risk factor for colorectal cancer. Dig Dis Sci, 57, 1586-97.

Saudi Cancer Registry. (2016). Cancer incidence report Saudi Arabia 2013.Retrieved from:http://www.chs. gov.sa/Ar/HealthCenters/NCC/CancerRegistry/ cancerRegistryReports/2013.pdf.

U.S. Preventive Services Task Force (2002). Screening for colorectal cancer: recommendation and rationale. Ann Intern Med, 137, 129-31.

van Jaarsveld CH, Miles A, Edwards R, Wardle J (2006). Marriage and cancer prevention: does marital status and inviting both spouses together influence colorectal cancer screening participation?. J Med Screen, 13, 172-6.

Walter LC, Lindquist K, Nugent S, et al (2009). Impact of age and comorbidity on colorectal cancer screening among older veterans. Ann Intern Med, 150, 465-73.

Whitlock EP, Lin JS, Liles E, Beil TL, Fu R (2008). Screening for colorectal cancer: a targeted, updated systematic review for the U.S. Preventive Services Task Force. Ann Intern Med, 149, 638-58.

Woo H, Lee J, Lee J, et al (2016). Diabetes mellitus and site-specific colorectal cancer risk in Korea: A case-control Study. J Prev Med Public Health, 49, 45-52.

World health orgnisation. (2012). Globocan 2012 : Estimated cancer incedince, mortality and incedince and prevalence worldwide in 2012.

Wu L, Yu C, Jiang H, et al (2013). Diabetes mellitus and the occurrence of colorectal cancer: an updated meta-analysis of cohort studies. Diabetes Technol Ther, 15, 419-27.

Zubaidi AM, AlSubaie NM, AlHumaid AA, et al (2015). Public awareness of colorectal cancer in Saudi Arabia: A survey of 1070 participants in Riyadh. Saudi J Gastroenterol, 21, 78.

\section{(ब) $(\mathbb{2}$}

This work is licensed under a Creative Commons AttributionNon Commercial 4.0 International License. 